\title{
Analysis of the primary and secondary microseisms in the wavefield of the ambient noise recorded in northern Poland
}

\author{
Simone Lepore ${ }^{1} \cdot$ Marek Grad $^{1}$
}

Received: 17 November 2017 / Accepted: 21 August 2018/Published online: 28 August 2018

(C) The Author(s) 2018

\begin{abstract}
Seasonal changes of the primary and secondary microseisms were analysed in the wavefield of the ambient noise recorded during the entire 2014 at the "13 BB star" array located in northern Poland, composed of thirteen, symmetrically arranged, broadband seismic stations. To that, spectral analysis, seismic interferometry, surface scalar wind speed distribution, and beamforming were used. Spectral analysis allowed to observe that a splitting of the secondary microseism peak was present in winter and autumn, and that the primary microseism peak was visible in spring, summer and autumn. Using seismic interferometry, the long-term characteristics of the noise wavefield were recognized. The seasonal variations of the secondary microseism source were described by means of the analysis of the surface scalar wind speed for each month. The splitting of the secondary peak was attributed to the interaction of a strong wind blowing from the North Sea with a weak wind blowing from the Baltic Sea. The seasonal variations of the primary microseism peak were characterized through the frequency-domain beamforming. The peak was identified during spring, summer and autumn, when the generated wavefield was coming from the Baltic Sea. The velocity of the wavefield was evaluated within the $2.0-5.0 \mathrm{~km} / \mathrm{s} \mathrm{range}$. The described mechanism of generation of the microseisms, based on the interaction of the nearby winds, was found to be consistent with the models reported in the literature.
\end{abstract}

Keywords Primary and secondary microseisms - Ambient noise - Broadband seismology $\cdot$ Fourier analysis . Seismic interferometry $\cdot$ Beamforming

\section{Introduction}

The ambient noise is present everywhere and is detected over a wide frequency band. Anthropogenic sources prevailingly cause the wavefield above $1 \mathrm{~Hz}$ (Mcnamara and Buland 2004; Lepore et al. 2016). In the 0.1-1 Hz range, the noise wavefield is generated by storms and interactions of wind-driven ocean waves travelling in opposite directions in the shallow (e.g. Schulte-Pelkum et al. 2004; Bromirski et al. 2005; Gerstoft and Tanimoto 2007) or deep water (e.g. Stehly et al. 2006; Kedar et al. 2008; Landès

Electronic supplementary material The online version of this article (https://doi.org/10.1007/s11600-018-0194-2) contains supplementary material, which is available to authorized users.

Simone Lepore

Simone.Lepore@fuw.edu.pl

1 Institute of Geophysics, Faculty of Physics, University of Warsaw, Ul. Pasteura 5, 02-093 Warsaw, Poland et al. 2010; Obrebski et al. 2012; Bromirski et al. 2013). The produced noise is identified in the literature as the secondary microseism (Longuet-Higgins 1950; Ardhuin et al. 2012; Stutzmann et al. 2012; Bromirski et al. 2005; Gualtieri et al. 2015). Below $0.1 \mathrm{~Hz}$, the wavefield is mainly dominated by the interaction between ocean waves and the seafloor close to the coastlines. In this case, the generated noise is known as the primary microseism (Hasselmann 1963; Bromirski and Duennebier 2002). The primary and secondary microseisms are clearly visible in the ambient noise wavefield when large impulsive sources (mostly earthquakes) are absent (Peterson 1993). The microseisms are distinctly related to atmospheric perturbations and ocean waves: some recent papers linked the pressure variations with the generation of microseisms (Gualtieri et al. 2015; Juretzek and Hadziioannou 2016; Möllhoff and Bean 2016), while others modelled several features of the primary and secondary microseisms (Ardhuin et al. 2011, 2012, 2015; Gualtieri et al. 2013, 2014). The accurate observations of the seasonal variations of the 
microseisms are the key to understand their physical aspects (Schimmel et al. 2011a).

Seismic interferometry (SI) is used to recognize the long-term characteristics of the ambient noise wavefield. By this technique, new seismic records are created by cross-correlating in time domain the existing ones. Namely, if a record at a random station $X$ is cross-correlated with another one at a station $Y$, a new record is obtained at $Y$ as generated from a source at $X$. As for the ambient noise, the Green's function has been demonstrated to be contained, at least partially, in the cross-correlation (CC) between a pair of two distant stations (Shapiro and Campillo 2004; Sabra et al. 2005a; Wapenaar and Fokkema 2006). Also for diffuse wavefields or isotropic noise source distribution it is possible to retrieve rather well the Green's function from the CC traces (Derode et al. 2003; Roux et al. 2005). An efficient retrieval of the Green's function is obtained by summing each CC trace with the consecutive ones and averaged over a long time, assuming the isotropic incidence of noise wavefield between station pairs (Shapiro and Campillo 2004; Sabra et al. 2005b; Campillo 2006). However, it has been shown recently that the distribution of the noise sources is generally neither isotropic nor stationary due to the presence of directional and temporal variations. Consequently, the empirical Green's function (EGF) is usually retrieved from the CC traces (Stehly et al. 2006; Yang and Ritzwoller 2008; Yao and van der Hilst 2009). Afterwards, surface waves can be extracted from the EGF (Halliday and Curtis 2008; Lepore et al. 2016) and the group velocity of the surface-wave arrivals can be estimated (Shapiro and Campillo 2004; Lepore et al. 2018). As in most situations (e.g. Stehly et al. 2006), the low-frequency band was used for the extraction of the surface waves. More detailed studies on the effects of the variability of the noise wavefield are required at high frequencies (Halliday and Curtis 2008): indeed, only very recently some papers analysed the generation of the highfrequency ambient noise (e.g. Gal et al. 2015; Gimbert and Tsai 2015; Möllhoff and Bean 2016).

To identify the spatial and temporal variations of the ambient noise wavefield, array techniques are used: all the corresponding records at each seismic station are joined together according to the frequency-domain beamforming (BF) algorithm (Lacoss et al. 1969; Rost and Thomas 2002; Roux 2009). Literature reports that the BF is the most advantageous technique for studying those features of the noise wavefield (e.g. Gerstoft and Tanimoto 2007; Koper et al. 2009). Nevertheless, the uncertainty in the source location constituted the main problem in investigating the variations of the noise wavefield: for this reason, most studies facing this difficulty limited the analysis of the source characterization only to the vertical component (Stehly et al. 2006; Yang and Ritzwoller 2008; Ruigrok et al. 2011). With the aim of going beyond this problem, in the present paper the variations of the noise wavefield were analysed for the $Z, N$ and $E$ components using the $\mathrm{BF}$ technique. The result of this analysis was the lowering of unwanted effects, for instance aliasing (Behr et al. 2013). Accordingly, the changes of the azimuth and the slowness (inverse of the velocity) were identified through the frequency-wavenumber power spectrum associated with the noise wavefield (i.e. beam power) as described by Lepore et al. (2016). As suggested by Obrebski et al. (2013) and Retailleau et al. (2014), the reliability of the BF technique was verified by determination of the azimuths for six chosen earthquakes shown in Fig. 1a. (Additional data are given in Online Resource 1.)

The purpose of the present paper is to analyse, by the application of the SI and BF techniques, the seasonal variations of the primary and secondary microseisms generated by the winds blowing from the North Sea and the Baltic Sea and detected in the wavefield related to the ambient noise, recorded during the whole 2014 at the "13 BB star" array located in northern Poland (Fig. 1a). This array, constituted by thirteen stations equipped with broadband seismometers $(120-50 \mathrm{~Hz})$, was arranged as shown in Fig. 1b (Grad et al. 2015). The details of the spatial disposition of the array stations are given in Lepore et al. 2016. According to the conservation of the energy flux, the average spectral features of the ambient noise can be extracted by calculating the related wavefield at the central station only (Van Tiggelen 2003). The symmetrical geometry of the array allows to gather the propagation characteristics of the surface waves at low frequencies for any orientation (Grad et al. 2015). The calculation of the beam power is possible at the very low frequencies, where the wavelengths are comparable to the intra-station distances (20-120 km) of the array (Harmon et al. 2008).

\section{Methods}

To further explore the primary and secondary microseisms in the ambient noise wavefield, we analysed the recorded data in the frequency and time domains. The detected spectrum for each noise record shows a combination of distant and local sources (e.g. Cessaro 1994). At frequencies higher than $1 \mathrm{~Hz}$, the spectrum of the noise wavefield is influenced by the sources located very close to the stations; on the other hand, at frequencies lower than $1 \mathrm{~Hz}$, the distant sources are dominant in the spectrograms (Lin et al. 2010). For our array, the stations were located in the forest or in the glades, allowing the safe retrieval of the spectral content of the noise wavefield (Grad et al. 2015). This wavefield is mainly formed by dispersive surface waves since the noise sources are mostly located on the 


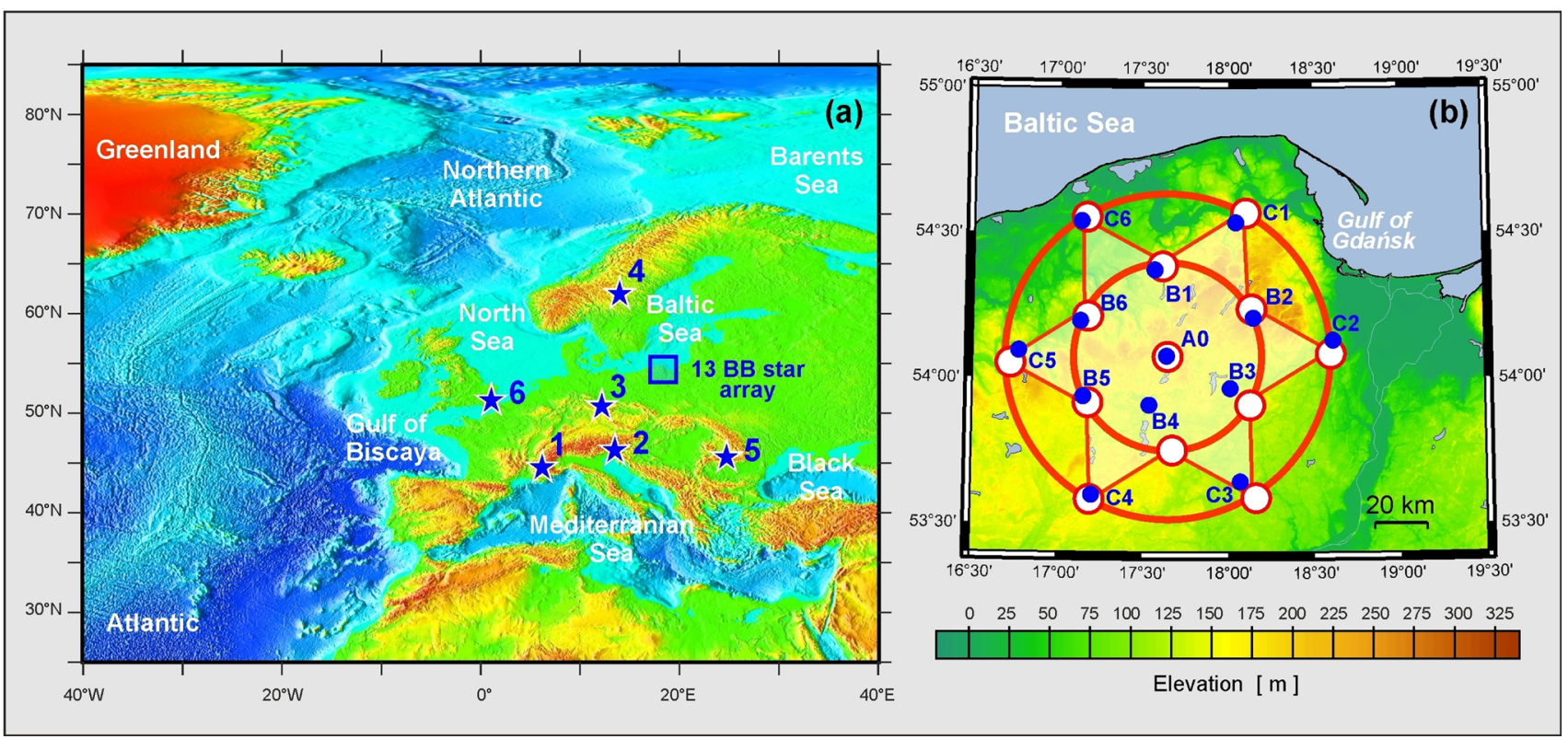

Fig. 1 a Location of the " 13 BB star" array in northern Poland on the background of the topography/bathymetry map (http://www.ngdc. noaa.gov/mgg/image/2minrelief.html) of Europe/Greenland and surrounding seas. The epicentres of the six earthquakes listed in Table 1 (see Online Resource 1) are marked with blue stars. b Arrangement of

Earth surface. To allow the extraction of surface waves from the wavefield, they are assumed to propagate without losing energy along the path between two stations (Schimmel et al. 2011b). An accurate knowledge of the spatial and temporal features of the noise wavefield sources is needed to perform a reliable passive seismic monitoring. That means a rather stable wavefield which, however, shows a high variability due to the seasonal distribution of the noise sources (Corela et al. 2017). Seasonal variations, indeed, are usually present in the spatial distribution of those sources: for example, the changes of the azimuth have significant effects on the direction of the wavefields (Zhan et al. 2013).

\section{Preprocessing}

Before carrying out the evaluation of the ambient noise spectrum and the retrieval of the surface waves from the wavefield, as well as the identification of the variations of the maximum beam power, the continuous noise records were preprocessed for each component, using $0.01 \mathrm{~s}$ as data sampling and $0.008-50 \mathrm{~Hz}$ as filtering band. At first, the records were cut into windows of $1 \mathrm{~h}$ length, from which the seismometer instrumental response, the mean and the linear trends were removed. The undesirable trends were thus eliminated, with the consequent deletion of large distortions that could cause the low-frequency contributions to vanish. Secondly, running-absolute-mean the "13 BB star" array on the background of the topography map. Red and white circles show the planned regular geometry of the network where broadband seismometers are placed in basic equilateral triangles with side lengths of about $30 \mathrm{~km}$. The navy-blue dots represent the final locations of the stations (A0, B1-B6, C1-C6)

normalization in time domain was employed on each 1-h noise window to remove the effects of huge amplitude events, such as earthquakes, and non-stationary sources. In this way, broadband ambient noise was emphasized by the elimination of all potential effects causing lack of clarity. Thirdly, normalization in frequency domain, founded on spectral whitening, was used in order to reduce the inconsistencies among single-station 1-h windows, conceivably produced by permanent local narrow-band or monochromatic sources (Bensen et al. 2007).

\section{Spectral analysis}

Once the noise records were preprocessed, spectral analysis was performed for identifying the frequency bands suitable to retrieve the surface waves. Given the random nature of the noise wavefield, only the power spectral density (PSD), namely the standard quantity expressing the noise in the frequency domain, can be evaluated (McNamara and Buland 2004). With the purpose of obtaining a thorough view of the noise records, we calculated the PSD as a function of time for the $Z, N$ and $E$ components at the central station of the array. According to Ruigrok et al. (2011) and Lepore et al. (2016), the noise spectrograms were obtained by stacking all the successive PSD curves in time domain for a whole day. Once identified the appropriate frequency band to characterize the primary and secondary microseisms, both were studied for 
the entire year to show the variations of the PSD amplitude each 5 days along with the seasonal changes.

\section{Seismic interferometry}

To extract the surface waves from the noise wavefield using the SI, we calculated the $\mathrm{CC}$ between all station pairs along the $Z, N$ and $E$ components for every month of 2014 . For each station pair, 1-h windows were selected from the recorded noise, preprocessed as described and cross-correlated in the $0.1-1 \mathrm{~Hz}$ frequency range. The processed $1-\mathrm{h}$ $\mathrm{CC}$ traces were then evaluated for an entire day and summed together. Finally, the resulting daily CC traces were stacked for each month (Lepore et al. 2016). For each trace, we chose the positive-time lag or the negative-time lag to retrieve the EGF based on the analysis of the dominant direction of the noise wavefield. Specifically, the positivetime lag was chosen when the dominant wavefield direction is from the (virtual) source to the receiver (Wapenaar 2006). Then, the CC traces showing the most proper retrieval of the EGF were selected from the entire collection of the traces; in turn, the group velocity of the surfacewave arrivals was evaluated from the EGF (Romanowicz 2002; Li et al. 2010). The features of the surface waves extracted from the wavefield were related to the seasonal variations of the secondary microseism.

\section{Beamforming}

To identify the variations of the maximum beam power, the correspondent noise records for the $\mathrm{Z}, \mathrm{N}$ and $\mathrm{E}$ components at all the array stations were merged by means of the frequency-domain BF ( $\mathrm{Li}$ et al. 2007, 2010). The beam power was calculated for 1-h noise records of any day, and, then, the results were stacked for each month in an appropriate frequency band (Behr et al. 2013). To avoid near-field effects, the minimum frequency $f_{\min }$ was set to

$f_{\text {min }}=\frac{v_{\text {aver }}}{3 \cdot \lambda_{\min }}=\frac{3 \mathrm{~km} / \mathrm{s}}{3 \cdot 20 \mathrm{~km}}=0.05 \mathrm{~Hz}$

where $v_{\text {aver }}$ is the average group velocity and $\lambda_{\min }$ is the minimum wavelength. To avoid aliasing, the maximum frequency $f_{\max }$ was fixed within the period suitable to resolve coherent surface waves (Harmon et al. 2008)

$f_{\max }=\frac{1}{10 \mathrm{~s}}=0.1 \mathrm{~Hz}$

The residual effects of the aliasing (e.g. the side lobe around $180^{\circ}$ ) are due to the array response (Grad et al. 2015). After the selection of the frequency band, the azimuth and the slowness were considered as variables: thus, the maximum beam power was evaluated as a function of the slowness and azimuth of the dominant beam (Ruigrok et al. 2011). Subsequently, the variations of the maximum beam power were related to the seasonal changes of the primary microseism. To test the reliability of the results, the BF method was employed to calculate the azimuth of the maximum beam power in the $0.05-0.1 \mathrm{~Hz}$ band for six selected earthquakes occurred in Europe with a magnitude of 4.5-5.6 and a distance of about 560-1320 km from the central station of the array. (Additional data are given in Online Resource 1.)

\section{Results and discussion}

The spectral analysis, the seismic interferometry and the beamforming were applied to the wavefield of the ambient noise recorded at the " 13 BB star" array during 2014 to analyse the seasonal variations of the primary and secondary microseisms caused by the winds blowing from the North Sea and the Baltic Sea.

\section{Variations of the primary and secondary microseisms}

The variations of the noise wavefield during 2014 are described through the analysis of the PSD curves as a function of time (Figs. 2, 3, 4).

The daily spectrograms obtained by the concatenation of the 1-h consecutive PSD curves, evaluated from the noise wavefield at the A0 station, are shown in the middle of Fig. 2 as frequency $v s$ time plots each 50 days for the $Z$, $N$ and $E$ components. The $2-50$ and $0.03-1 \mathrm{~Hz}$ frequency ranges represent the two main bands where the noise persists for the whole year. In the high-frequency range $(2-50 \mathrm{~Hz})$, the noise wavefield amplitude is the lowest during winter and autumn, while it is the highest in spring and summer. Surface waves in this frequency band are produced by local noise sources not related to the ocean activity, prevalently anthropogenic and less strong during night-time than day-time (Lepore et al. 2016). For each day, a remarkable correlation exists between the duration of the strongest noise and the length of the daylight, measurable from the plots of the sun elevation above the horizon, as shown for the same days at the top of Fig. 2. Moreover, the length of the daylight is shorter in winter and autumn, whereas it is larger in spring and summer. In the low-frequency range $(0.03-1 \mathrm{~Hz})$, the surface waves are caused by the interaction of wind-driven ocean waves in shallow or deep water. Two small bands can be observed: the first, coloured in light cyan, goes from 0.03 to $\sim 0.1 \mathrm{~Hz}$; the second, coloured in yellow-green, goes from $\sim 0.1$ to $1 \mathrm{~Hz}$. The first band is rather clear during spring and summer and almost absent during autumn and winter. On the contrary, the second band is well visible 


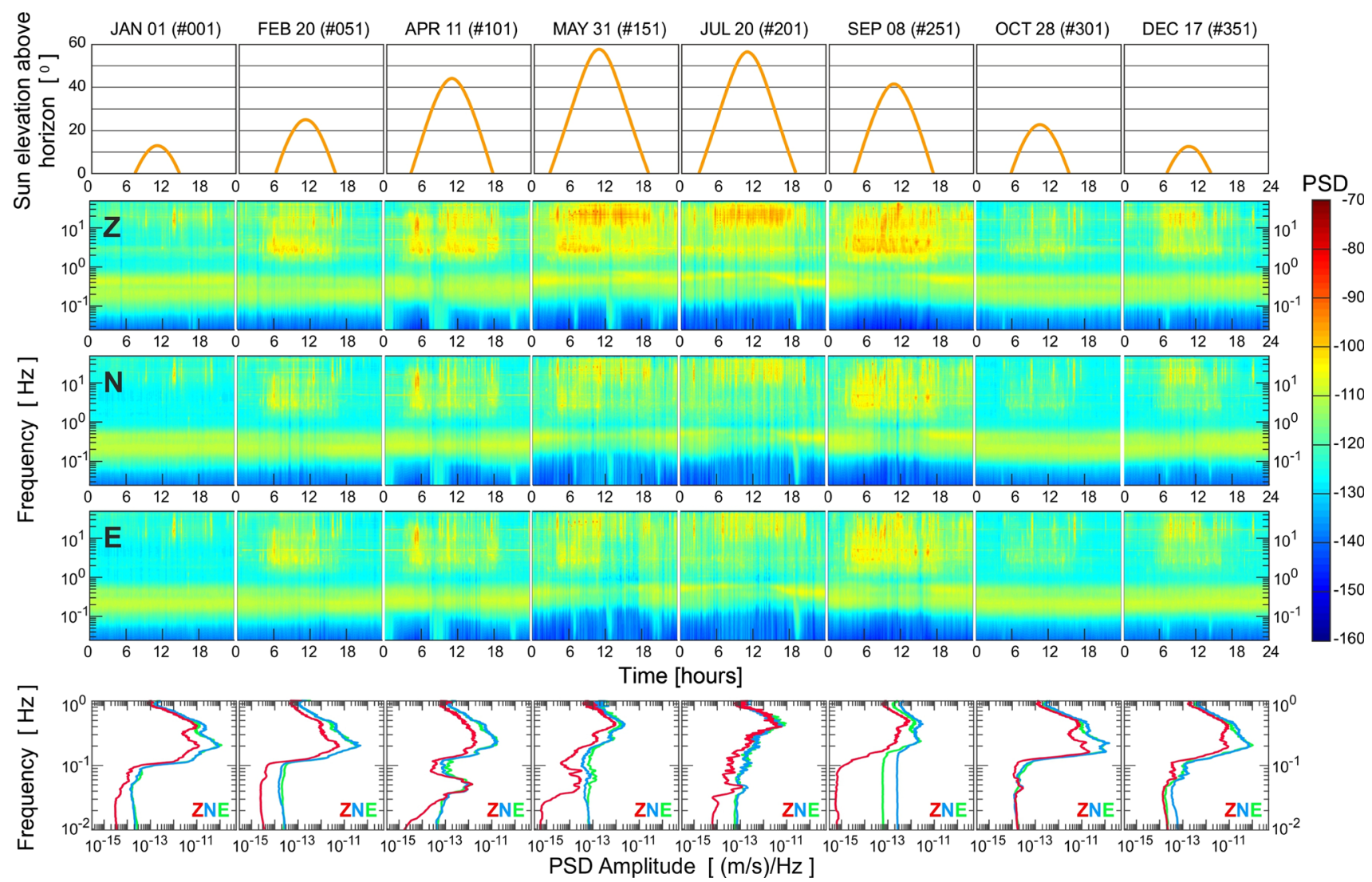

Fig. 2 Top: sun elevation above horizon each 50 days in 2014; middle: comparison between eight spectrograms evaluated in the same days for $Z, N$ and $E$ components at the central station A0. Three frequency bands are observed in which the noise is continuously present during the whole period, namely $0.03-0.1 \mathrm{~Hz}$ (coloured in

during the whole year. The different colours highlight the jump present in the PSD between the two bands. To characterize in detail this jump, the curves of the PSD amplitude as a function of the frequency are shown for the $Z, N$ and $E$ components at the bottom of Fig. 2. In spring and summer, two peaks are observed: the first, within $0.03-0.1 \mathrm{~Hz}$ and $10^{-12}-10^{-13}(\mathrm{~m} / \mathrm{s}) / \mathrm{Hz}$, corresponds to the primary microseism peak; the second, within $0.1-1 \mathrm{~Hz}$ and $10^{-10}-10^{-12}(\mathrm{~m} / \mathrm{s}) / \mathrm{Hz}$, corresponds to the secondary microseism peak. The primary microseism peak has a very low amplitude in winter, little higher in autumn, while the highest amplitude is reached in spring and in summer. The secondary microseism peak has the highest amplitude in winter and autumn; at the same time, a splitting into two peaks is observed in the $0.2-0.8 \mathrm{~Hz}$ range. In spring and summer, the amplitude is the lowest, and only one peak is observed within the same frequency range.

The variations of the primary and secondary microseisms during the entire 2014 are shown in Fig. 3 by the plots of the PSD amplitude every 5 days as a function of frequency for $Z, N$ and $E$ components at the A0 station. For light cyan), 0.1-1 Hz (yellow-green) and 2-50 Hz (yellow-red). The scale of the power spectral density is in $10 \log (\mathrm{m} / \mathrm{s}) / \mathrm{Hz}$; bottom: rotated plots of power spectral density amplitude curves versus frequency in the same days for the three components. The power spectral density amplitude is in $(\mathrm{m} / \mathrm{s}) / \mathrm{Hz}$

each of the three plots, the first curve from the bottom (1 January 2014) is in its proper scale, whereas all the other curves are moved up by a $\Delta x$ shift indicated in the rightbottom corner. The same set of colours (black, cyan, blue, purple, dark blue, fuchsia, red, orange, light green, green) is repeated every ten curves. In the $0.03-0.1 \mathrm{~Hz}$ frequency range, significant maxima are observed in several cases (days 21, 26, 61, 76, 81, 101, 131, 136, 146, 151, 166, 186, 201, 206, 226, 236, 246, 261, 266, 281, 311, 321, 326, 341, 355). The PSD amplitude of the primary microseism peak, commonly observed very close to the oceanic coastlines, ranges between $10^{-12}$ and $10^{-15}(\mathrm{~m} / \mathrm{s}) / \mathrm{Hz}$. In most cases, two maxima are detected in the $0.1-1 \mathrm{~Hz}$ frequency range. As reported in the literature (e.g. Koper and Burlacu 2011, 2015), the splitting of the secondary microseism peak implies the simultaneous activation of two wind-driven ocean sources.

To analyse the seasonal changes of the primary and secondary microseisms, five PSD amplitude curves for each season were selected randomly from Fig. 3 for the $\mathrm{Z}$ component. These curves, shown in Fig. 4, are gathered in 
Fig. 3 Power spectral density amplitude as a function of frequency evaluated for each 5 days in 2014 for the three components. Only the lowest curve (1 January 2014) is in the proper amplitude scale. All next curves are moved up by $\Delta x$ shown by vertical bar in the lower-right corner of each plot. The same set of colours (black, cyan, blue, purple, dark blue, fuchsia, red, orange, light green, green) is repeated every ten curves. In the $0.1-1 \mathrm{~Hz}$ range, the secondary microseism peak is split in most cases into two peaks. In several cases, the primary microseism peak is observed below $0.1 \mathrm{~Hz}$

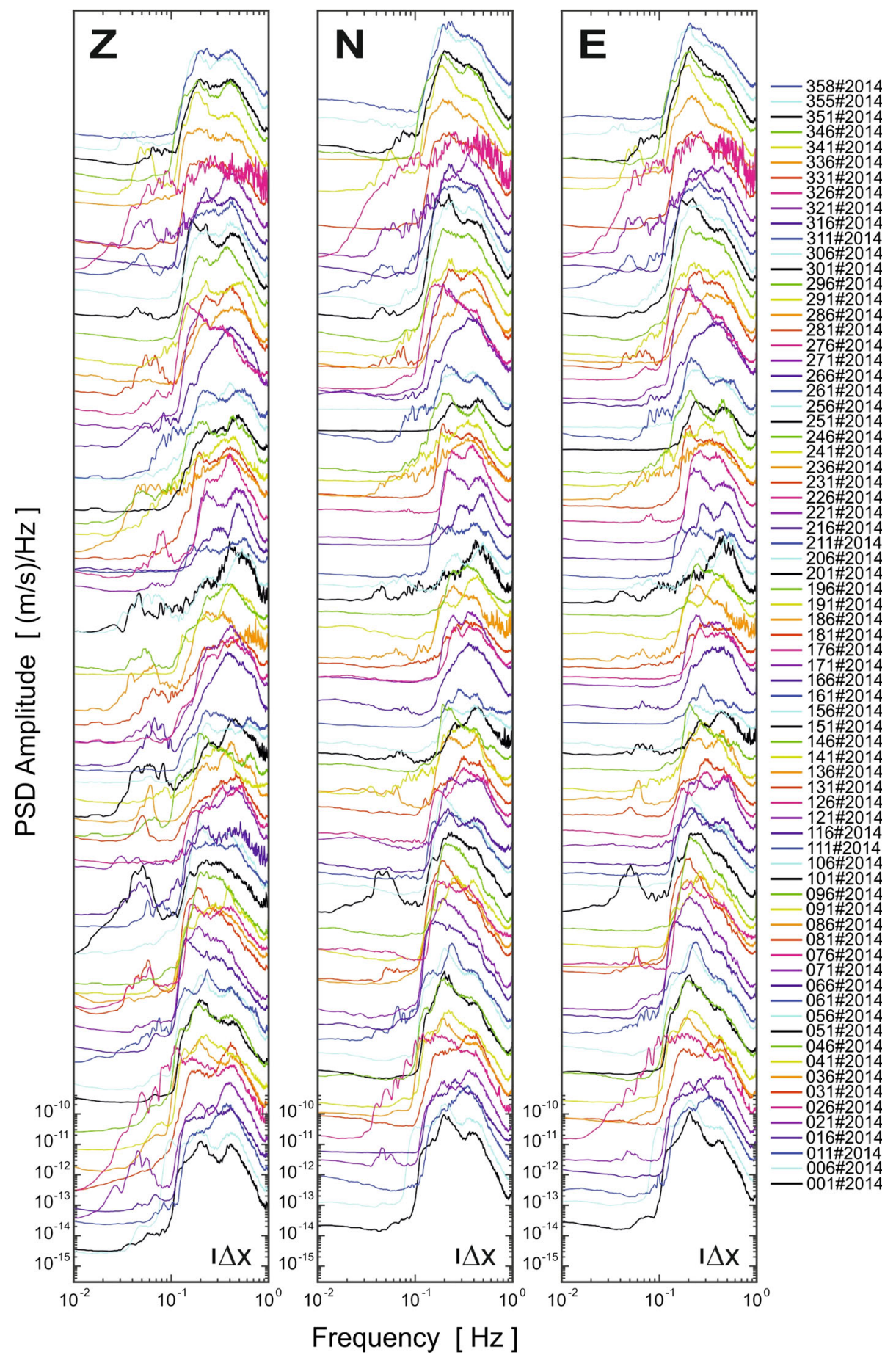

four different plots for winter, spring, summer and autumn. In winter, we observe that the primary microseism peak has the maximum amplitude of $\sim 10^{-13}(\mathrm{~m} / \mathrm{s}) / \mathrm{Hz}$ and the secondary microseism peak is split into two peaks, the first around $0.2 \mathrm{~Hz}$ and the second around $0.4 \mathrm{~Hz}$. During spring, the primary peak has the maximum amplitude of $\sim 10^{-12}(\mathrm{~m} / \mathrm{s}) / \mathrm{Hz}$, while the secondary one presents a single peak either around $0.2 \mathrm{~Hz}$ or around $0.4 \mathrm{~Hz}$. In summer, the primary peak has the maximum amplitude of $\sim 10^{-12}(\mathrm{~m} / \mathrm{s}) / \mathrm{Hz}$, while the secondary one generally presents a main peak around $0.4 \mathrm{~Hz}$. Only for the day 261 another peak around $0.2 \mathrm{~Hz}$ is also detectable for the secondary peak. During autumn, the maximum amplitude of primary microseism peak is a bit higher than $10^{-13}(\mathrm{~m} / \mathrm{s}) /$ $\mathrm{Hz}$ and the splitting of the secondary microseism peak is again evident in the $0.2-0.4 \mathrm{~Hz}$ range. 

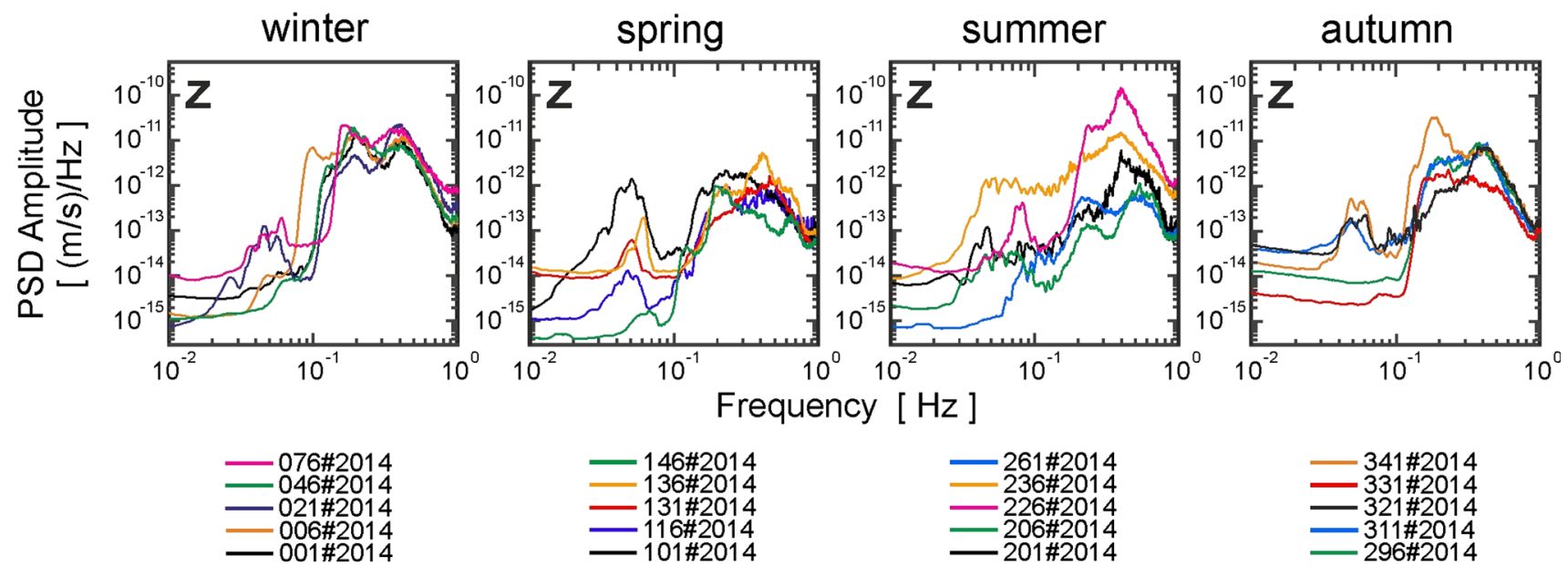

Fig. 4 Power spectral density amplitude curves for the $Z$ component randomly selected from Fig 3, gathered for winter, spring, summer and autumn

\section{Seasonal changes of the secondary microseism investigated by seismic interferometry}

The seasonal variations of the secondary microseism during the whole 2014 are described through the study of surface-wave arrivals on the stacked CC traces for each month. According to the literature (Buffoni et al. 2018; Kimman et al. 2012; Schimmel et al. 2017; Ventosa et al. 2017), only the CC traces along $Z$ component are shown from all the traces calculated along the $Z, N$ and $E$ components.

In Fig. 5, time-distance plots for the $Z$ component in the $0.1-1 \mathrm{~Hz}$ frequency band show a selection of the stacked daily CC traces between all the station pairs of the array, for January, April and September 2014. As described before, only the traces showing the most correct retrieval of the EGF were chosen from the entire collection. Indeed, to avoid the crowding of the traces, some of them pertaining to station pairs with similar interdistances, as well as some others showing low signal-to-noise ratio, were removed. For all the 3 months, the EGF is always retrieved from the positive-time lag of each trace, implying that the source of secondary microseisms is located in the north of the array. The faster surface-wave arrivals are identifiable along the line connecting the points of coordinates $\sim 13 \mathrm{~s}$ at $\sim 20$ $\mathrm{km}$ and $\sim 78 \mathrm{~s}$ at $\sim 117 \mathrm{~km}$ with an average group velocity of $1.5 \mathrm{~km} / \mathrm{s}$, while the slower ones are recognizable along the line connecting the points having coordinates $\sim 20 \mathrm{~s}$ at $\sim 20 \mathrm{~km}$ and $\sim 117 \mathrm{~s}$ at $\sim 117 \mathrm{~km}$ with an average group velocity of $1.0 \mathrm{~km} / \mathrm{s}$. In January, a month representing the winter season, both the faster and the slower arrivals are observable. In April, standing for the spring season, the faster surface-wave arrivals are well visible, while the slower ones are poorly observable. In September, representing the transition between summer and autumn, both the faster and the slower arrivals are again detectable. The dispersion of the surface waves has been discussed in detail by Lepore et al. (2018). It must be underlined that the primary microseism was not investigated by the SI because of the very low amplitudes of surface waves at frequencies lower than $0.1 \mathrm{~Hz}$, especially for weak noise sources (Ardhuin et al. 2012).

\section{Sources of noise wavefield for the secondary microseism}

To characterize the sources of the noise wavefield for the secondary microseism, the surface scalar wind speed, obtained from NCEP-DOE AMIP-II Reanalysis (Kanamitsu et al. 2002), is shown for each month of the 2014 in Fig. 6 as a function of latitude and longitude in the same frame of Fig. 1a. The white dot in each of the twelve plots indicates the location of the array, and the scale at the bottom shows the values of the surface scalar wind speed within $0-20 \mathrm{~m} / \mathrm{s}$. In winter, a strong wind is detected in the area delimited by $40 \mathrm{~W}-10 \mathrm{E}$ and $40 \mathrm{~N}-70 \mathrm{~N}$, while a weak wind is identified in the region defined by $10 \mathrm{E}-40 \mathrm{E}$ and $50 \mathrm{~N}-70 \mathrm{~N}$. The kinetic energy of the strong wind is decreasing from January to March, whereas the energy of the weak wind remains nearly unaltered. According to Lepore et al. (2016), we observe the interaction between two sources of noise wavefield, namely the strong wind blowing from the North Sea with speed within the $12-20 \mathrm{~m} / \mathrm{s}$ range and the weak wind blowing from the Baltic Sea with speed in the $2-8 \mathrm{~m} / \mathrm{s}$ range. During spring and summer, the strong wind blowing from the North Sea has a kinetic energy much lower than that of the weak wind blowing from the Baltic Sea. It means that one source of noise wavefield is mainly present during these two seasons. In autumn, the strong and weak winds are again identified 

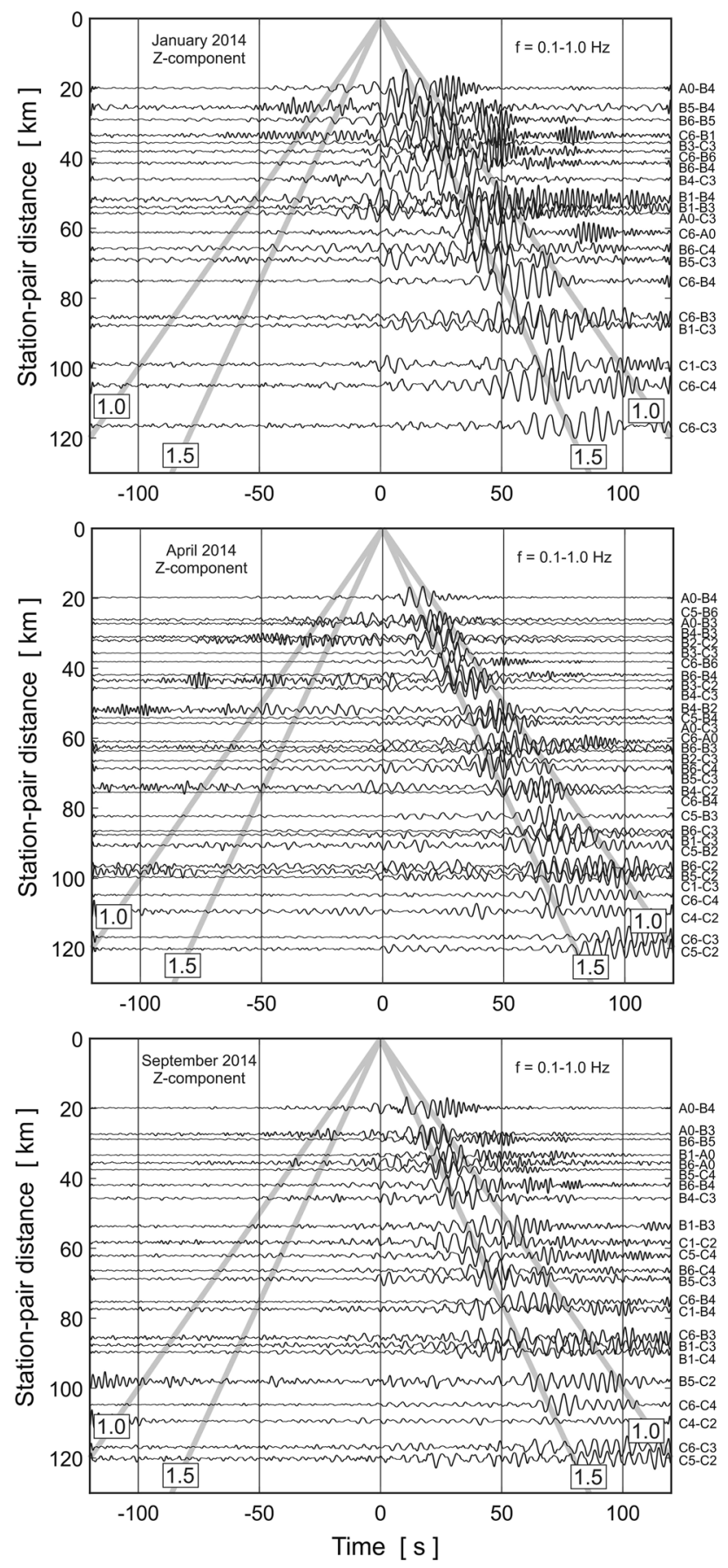

Fig. 5 Time-distance plots for the $Z$ component in the $0.1-1 \mathrm{~Hz}$ frequency band showing a selection of the stacked daily crosscorrelation traces, for January, April and September 2014. To avoid crowding of traces, some of them related to station pairs with similar interdistances, as well as some others having low signal-to-noise ratio, were removed. The thick grey lines are drawn to make easier the recognition of the surface-wave arrivals, whose velocities are reported in the box on the top of the lines

in almost the same areas defined during winter. The kinetic energy of the strong wind is increasing from October to December, whereas the energy of the weak wind remains nearly constant. The interaction between two sources of noise wavefield is again observed as in winter.

\section{Seasonal changes of the primary microseism investigated by beamforming}

The seasonal variations of the primary microseism during 2014 are characterized by studying the beam power of the noise wavefield for the $\mathrm{Z}, \mathrm{N}$ and $\mathrm{E}$ components for each month. Before that, the frequency-domain $\mathrm{BF}$ technique was validated by the identification of the epicentre azimuths for six selected earthquakes. (Additional data are given in Online Resource 1.)

To show the seasonal variations of the primary microseism, the beam power for each month is reported in Fig. 7 for the $\mathrm{Z}$ component in the $0.05-0.1 \mathrm{~Hz}$ frequency band as a function of azimuth and slowness. (The beamformer results for the $\mathrm{N}$ and $\mathrm{E}$ components are shown in Online Resource 2.) In each of the twelve plots the beam power is in its own scale to better highlight the dominant beams, whose angular resolution has a maximum value of $\sim 10^{\circ}$ with a weak azimuthal dependence according to the geometry of the array (Koper and Burlacu 2011, 2015, 2016). Aliasing due to the array response is still detectable, and notwithstanding the beam power is stacked for each month to avoid such undesired effects. For example, the beamformer results in August and December look similar, even though the dominant beam is located once around $60^{\circ}$ and in the other case around $300^{\circ}$. However, the amplitude of the side lobes generated by the aliasing is considerably lower than that of the dominant beam for each month. During winter, the dominant beam moves from $230^{\circ}$ (in January) to $355^{\circ}$ (in March) and its amplitude decreases progressively. Thus, the wavefield generated by the main source of the noise arrives from the North Sea, far away from the array so that the amplitude of the primary microseism peak is very low. During spring, the dominant beam ranges between $10^{\circ}$ and $80^{\circ}$, and the beam-power amplitude first decreases from April to May and then slightly increases from May to June, keeping always higher than that in winter. Hence, the wavefield generated by the main source of the noise comes from the Baltic Sea, very close to the array, thus allowing the detection of the primary microseism peak. During summer, the dominant beam moves between $320^{\circ}$ (in September) and $80^{\circ}$ (in August). The beam-power amplitude is stronger in July and August than in September: hence, the primary microseism peak is visible when the wavefield generated by the main source is coming from the Baltic Sea. During autumn, the dominant beam ranges between $290^{\circ}$ (in December) and $80^{\circ}$ (in November). The strongest amplitude is observed in November, meaning that the primary microseism peak is observable when the wavefield 

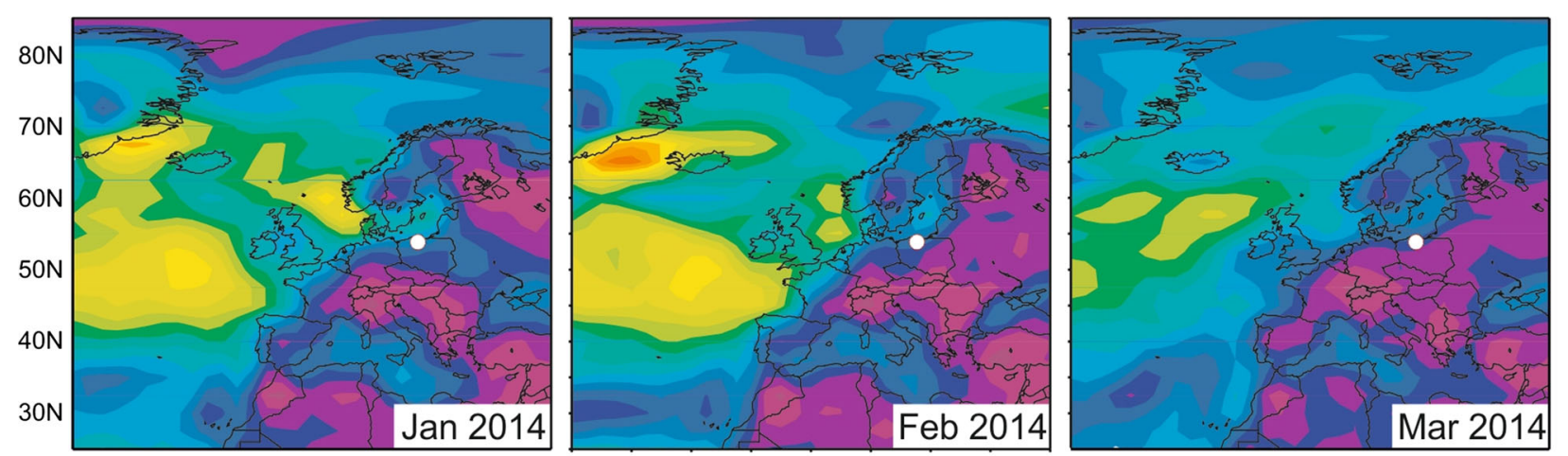

$\frac{\bar{\Phi}}{\stackrel{\frac{1}{5}}{\zeta}}$
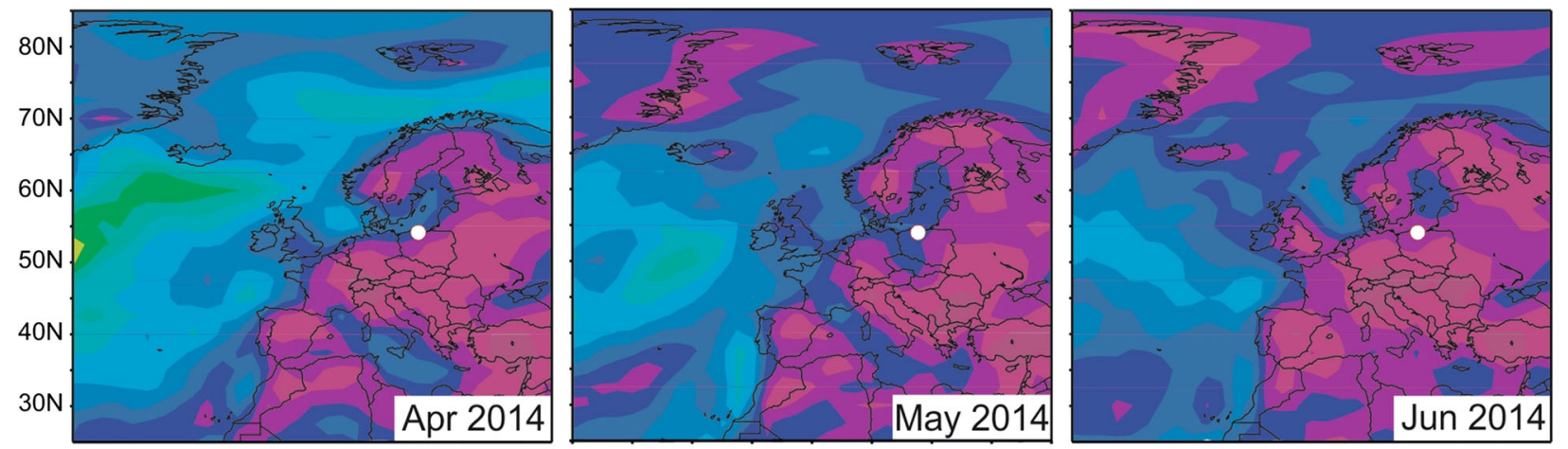

을
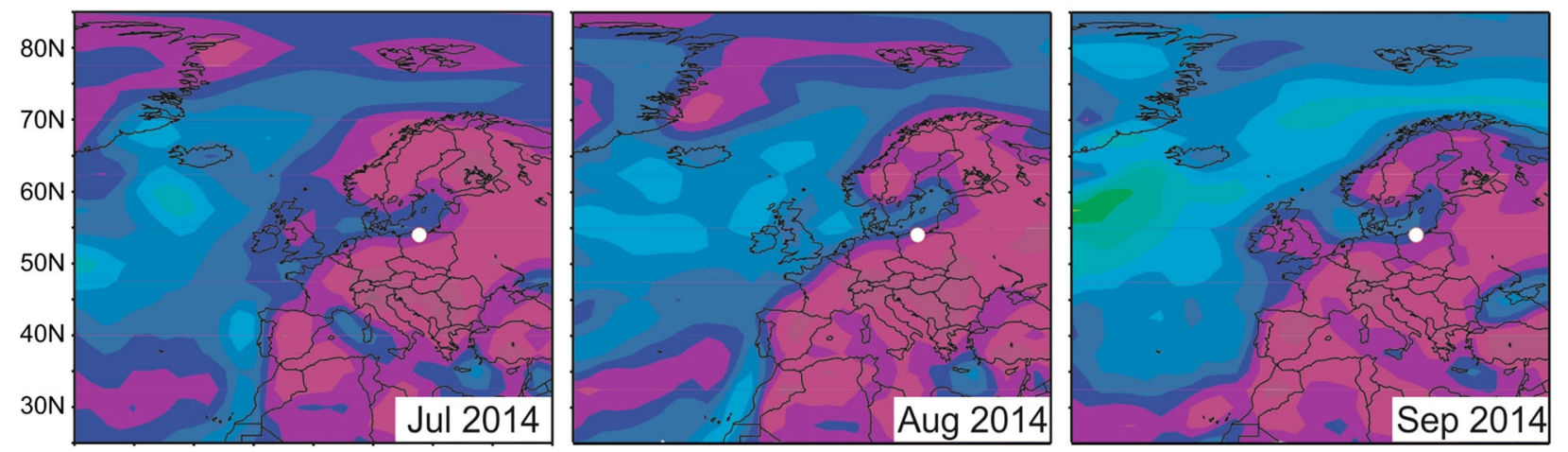

这
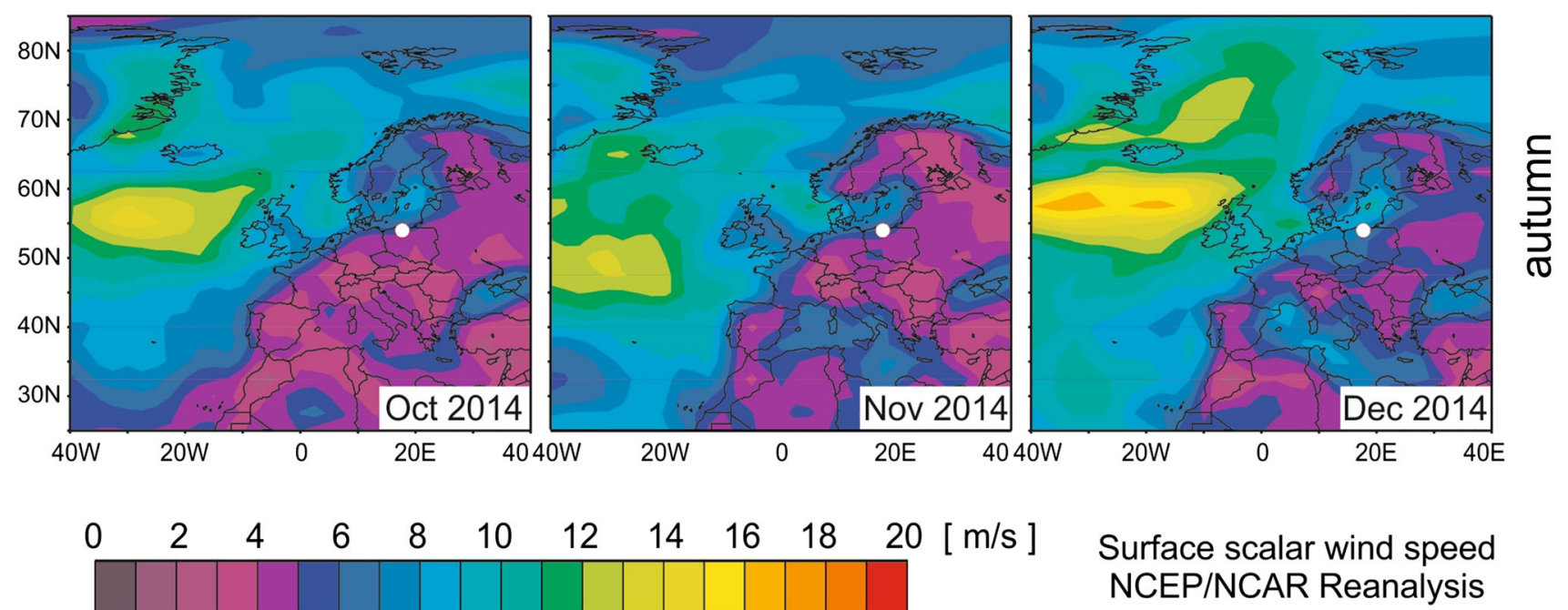

\section{Surface scalar wind speed} NCEP/NCAR Reanalysis

Fig. 6 Plots of the spatial distribution of the surface scalar wind speed in m/s from NCEP-DOE AMIP-II Reanalysis database for each month of 2014 in the same frame of Fig 1a. White dots show the location of the "13 BB star" array 

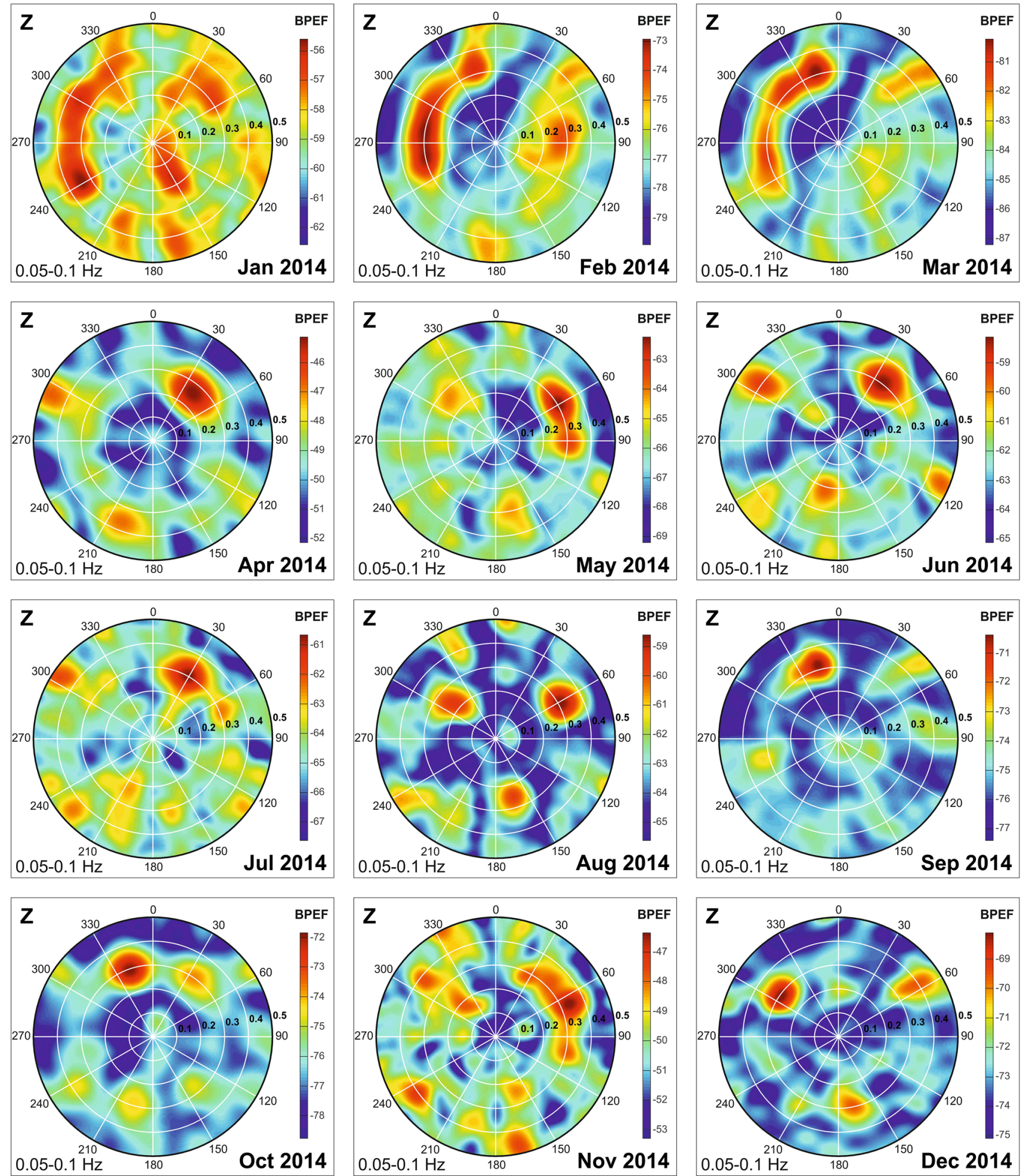

Fig. 7 Beam-power plots for each month of 2014 for the $Z$ component. The scale of the beam power is different for each month to better highlight the dominant beams. The same plots for the $N$ and $E$ components can be found in Online Resource 2

generated by the main source arrives from the Baltic Sea. It is worth to highlight that the beam power for the secondary microseism is not shown since we observed in the beamformer results that for frequencies above $0.1 \mathrm{~Hz}$ the aliasing effect became relevant making difficult the identification of the main source (Harmon et al. 2008). 


\section{Features of the wavefield related to the primary microseism}

To define more precisely the direction and to calculate the velocity of the wavefield associated with the primary microseism, azimuth and slowness (inverse of velocity) for the dominant beam were extracted from the beam power evaluated each 5 days during the entire 2014.
The variations of the azimuth are reported in the scatter and histogram plots shown in Fig. 8 for the $Z, N$ and $E$ components. In the scatter plot, the azimuth values are marked by large filled circles. Most of the circles gather into the $30^{\circ}-90^{\circ}$ and $300^{\circ}-360^{\circ}$ ranges: since the highest concentration is in the upper part, the first range is marked in light grey and the second one is highlighted in dark grey. The histogram plots shown in Fig. 8 for the Z, N and E components represent the concentration of the azimuth
Fig. 8 Azimuth variations extracted from the maximum beam power evaluated each 5 days during the whole 2014 for $Z, N$ and $E$ components. Left: scatter plots, in which the azimuth values are marked by large filled circles. The dark grey and the light grey bands highlight the two ranges in which most of the circles are gathered. Right: histogram plots showing the concentration of the azimuth values (number of counts). For each plot, the round angle is divided into 12 bars each one thirty degrees large
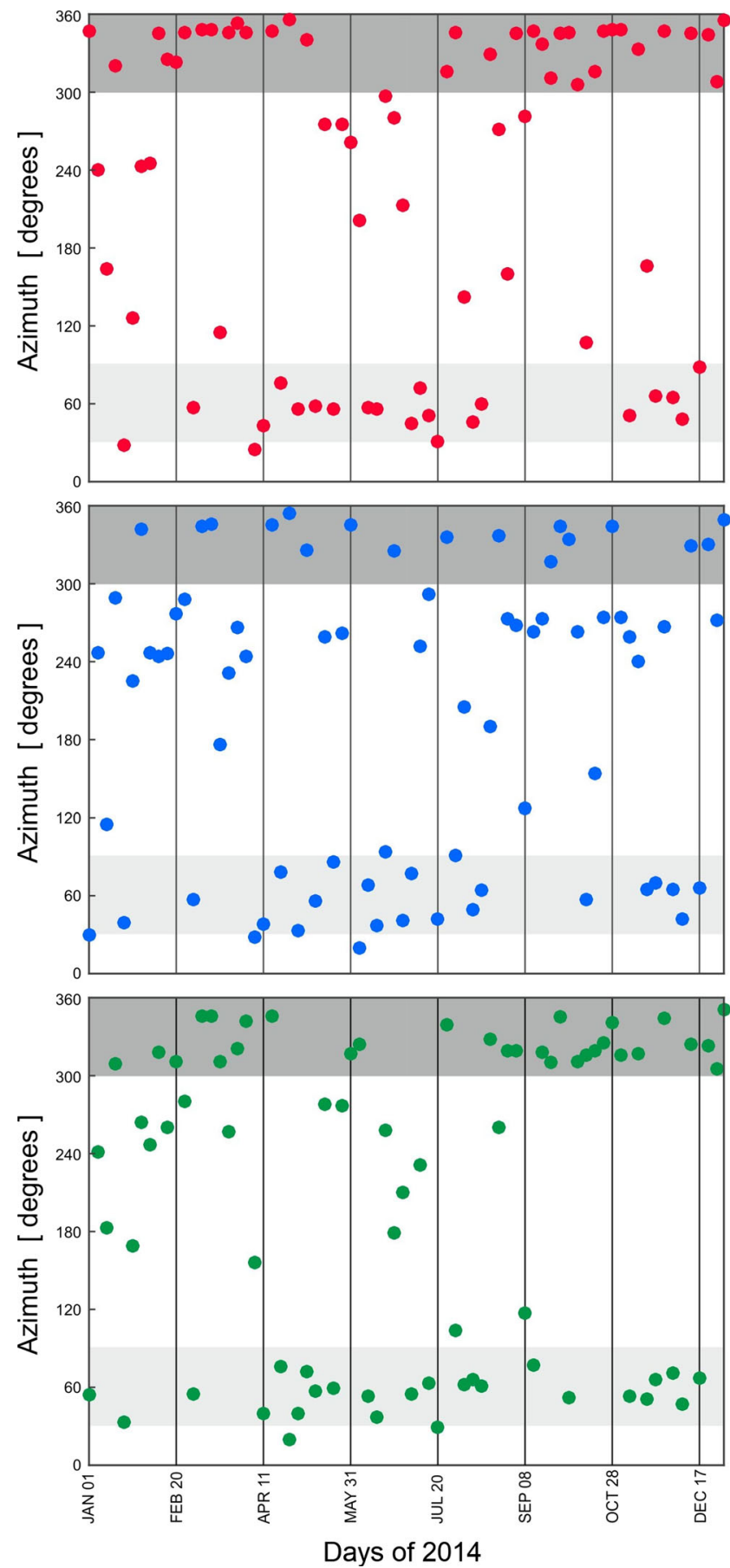
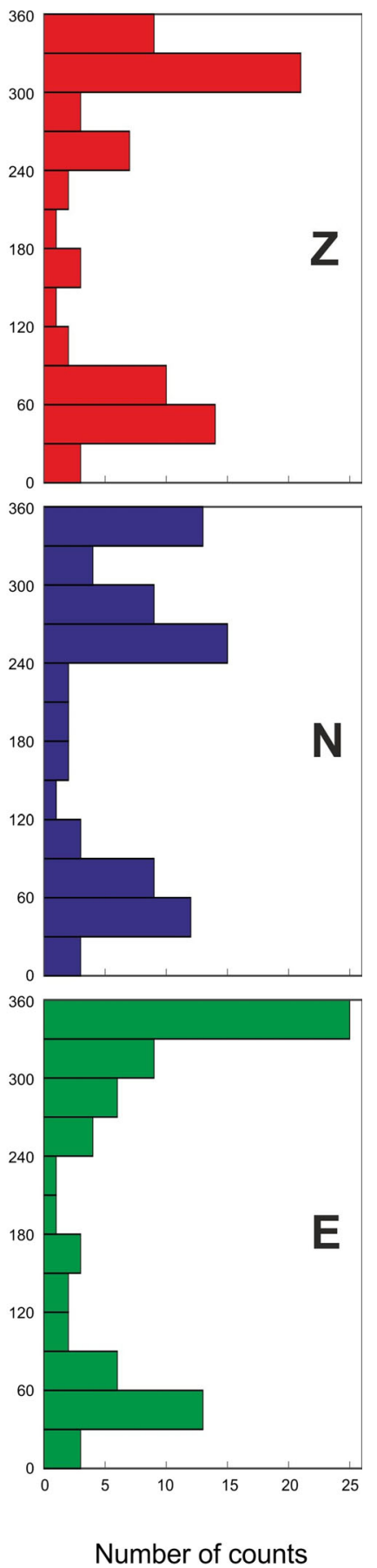
values (number of counts). In each plot, the division chosen for the round angle is $30^{\circ}$, corresponding to 12 bars. For the $Z$ component, the bars within the $30^{\circ}-90^{\circ}$ and $300^{\circ}-360^{\circ}$ ranges are more pronounced than the others. The distribution of the bars for the $N$ component present three zones of maximum elongation, that is $30^{\circ}-90^{\circ}, 240^{\circ}-300^{\circ}$ and $300^{\circ}-360^{\circ}$. The distribution for the $E$ component displays the longest bars within the ranges $30^{\circ}-90^{\circ}$ and $300^{\circ}-360^{\circ}$. Collecting all the identified ranges, we confirm what found previously for the azimuth variations using the scatter plots.

The variations of slowness (and velocity) are shown in Fig. 9 each 5 days for the $Z, N$ and $E$ components. It can be immediately seen that the related values are confined within the $2.0-5.0 \mathrm{~km} / \mathrm{s}$ velocity range. For the $Z$ component, the values range within $2.0-3.8 \mathrm{~km} / \mathrm{s}$; for the $\mathrm{N}$ component, the lowest value $(2.0 \mathrm{~km} / \mathrm{s})$ is noticed in January and August, whereas the highest is found in May $(4.2-4.8 \mathrm{~km} / \mathrm{s})$; for the E component, the values are contained within $2.1-3.9 \mathrm{~km} / \mathrm{s}$. Analysing together the three components, two zones are observed where most of the values are gathered: as done for the scatter plots in Fig. 9, the upper band, containing most of the points, is highlighted in dark grey, while the lower band is marked in light grey. For what concerns the velocity values, they range within $3.1-3.7 \mathrm{~km} / \mathrm{s}$ in the upper band, whereas they vary within $2.0-2.8 \mathrm{~km} / \mathrm{s}$ in the lower band. Therefore, the two bands specify the velocity range for the azimuth bands described before. The very large variations in velocity should be related to the calculation of the beam power for the $0.05-0.1 \mathrm{~Hz}$ frequency band, not for a specific value of frequency (Ruigrok et al. 2011).

\section{Conclusions}

The study of the seasonal variations of the primary and secondary microseisms was performed on the ambient noise recorded during the whole 2014 at the " 13 BB star" array located in northern Poland, by means of spectral analysis, seismic interferometry by cross-correlation, surface scalar wind speed distribution and frequency-domain beamforming.

By applying spectral analysis, the primary and secondary microseisms were recognized in the $0.03-0.1$ and $0.1-1 \mathrm{~Hz}$ frequency ranges, respectively. The primary microseism peak was well visible in spring and summer, slightly observable in autumn and poorly detectable in winter: its amplitude was relatively low during the whole year. On the contrary, the secondary microseism peak was always well visible: in winter and autumn it was split into two peaks placed in the $0.2-0.4 \mathrm{~Hz}$ range.

To outline the seasonal variations of the secondary microseism, the surface-wave arrivals were observed in the empirical Green's function retrieved from the cross-correlation traces obtained by stacking for each month the daily traces calculated for the $Z$ component in the $0.1-1 \mathrm{~Hz}$ frequency band. Two sets of surface-wave arrivals were recognized: the faster showed an average group velocity of $\sim 1.5 \mathrm{~km} / \mathrm{s}$, while the slower one displayed a velocity of $\sim 1.0 \mathrm{~km} / \mathrm{s}$. In winter, both the faster and the slower arrivals were well identified. In spring and summer, the faster arrivals were well visible, while the slower ones were poorly observable. In autumn, both the faster and the slower surface-wave arrivals were again detectable.
Fig. 9 Variations of the velocity extracted from the maximum beam power evaluated each 5 days during the entire 2014 for $Z, N$ and $E$ components. The dark grey and the light grey bands mark the two ranges in which most of the values are gathered

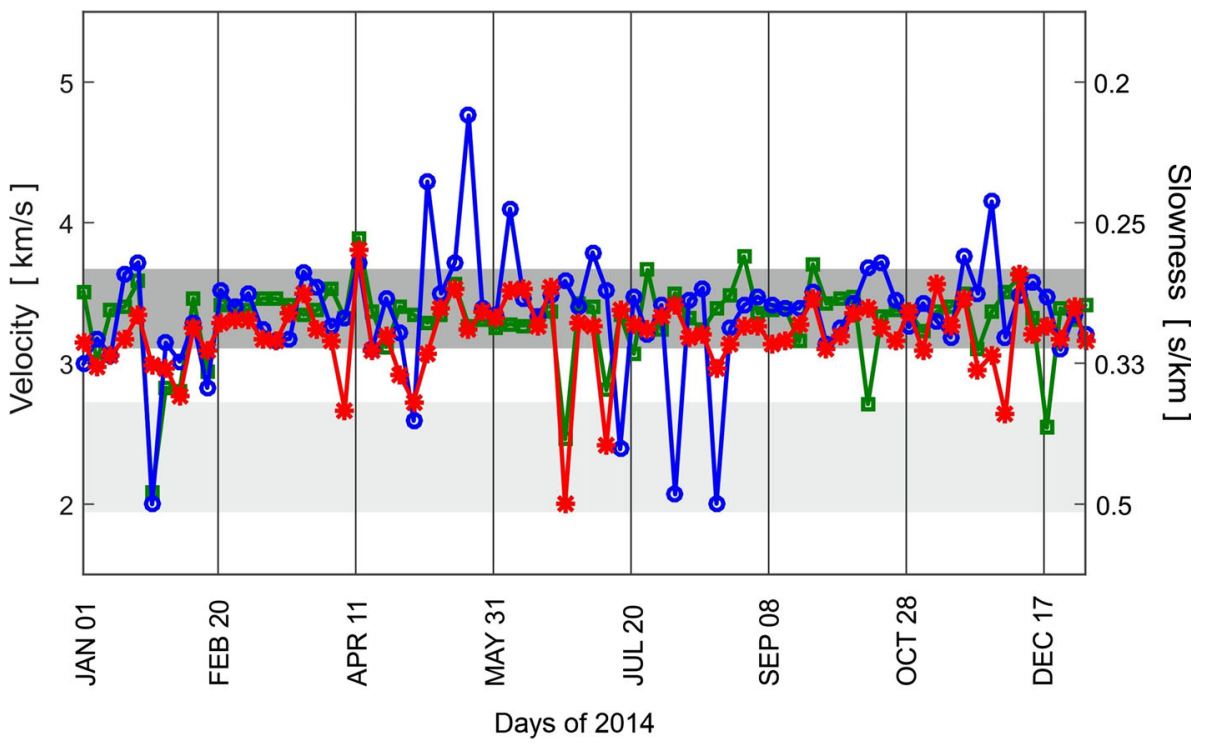

components: $-*-\mathbf{Z} \rightarrow \mathbf{N} \rightarrow-\mathbf{E}$ 
By analysing the spatial distribution of the surface scalar wind speed within $0-20 \mathrm{~m} / \mathrm{s}$ for each month from the NCEP-DOE AMIP-II Reanalysis database, two sources of noise wavefield were identified. The stronger wind was located in the North Sea with speed within the range $12-20 \mathrm{~m} / \mathrm{s}$, while the weaker wind in the Baltic Sea having speed in the range $2-8 \mathrm{~m} / \mathrm{s}$. During autumn and winter, the interaction between the strong and weak winds was observed. During spring and summer, the kinetic energy of the strong wind was much lower than that of the weak wind.

The seasonal variations of the primary microseism were characterized by evaluating the beam power for each month of 2014 in the $0.05-0.1 \mathrm{~Hz}$ frequency band for the $Z, N$ and $E$ components. Before the application of the beamforming, the reliability of the method was proved by the evaluation of the epicentre azimuth for six earthquakes in the same frequency band. Only in one case it was observed that the agreement between the azimuth associated with the maximum beam power and the azimuth from known geographic coordinates was not satisfactory: thus, it can be safely concluded that the technique is generally reliable. By analysing the variations of the dominant beam, it was shown that in winter the wavefield generated by the main source of noise was coming from the North Sea, far away from the array, thus making very low the amplitude of the primary microseism peak. For the rest of the year, the wavefield generated by the main source was coming from the Baltic Sea, very close to the array, so as to cause the detection of the primary microseism peak. Evaluating the azimuth of the dominant beam each five days, the two sources of the wavefield were identified within the $30^{\circ}-90^{\circ}$ and $300^{\circ}-360^{\circ}$ regions. Calculating the slowness from the maximum beam power in the same days, we found that the average velocity of the wavefield related to the primary microseism was in the $2.2-3.8 \mathrm{~km} / \mathrm{s}$ range.

To sum up, the mechanism of generation of the primary and secondary microseisms in northern Poland described in this paper is based on the interaction of the nearby winds blowing from the neighbouring seas. This model is consistent with the models generally accepted in the literature concerning the generation of microseisms, while the observed splitting of the secondary microseism peak has been described up to now only by a few authors.

Acknowledgements This work was supported financially by National Science Centre Poland (NCN grant DEC-2011/02/A/ST10/00284). The public domain GMT software (Wessel and Smith 1998) was used to produce array map. We thank Dr. Elmer Ruigrok for the development of the MATLAB codes here used. Surfaces of the Earth in the colour relief images ETOPO2v2 from NOAA/NGDC database were employed for the topographic plans (https://www.ngdc.noaa.gov/ $\mathrm{mgg} /$ image/2minrelief.html). Wind speeds are obtained from the NCEP-DOE AMIP-II Reanalysis database (https://www.esrl.noaa. gov/psd/data/gridded/data.ncep.reanalysis2.html).

\section{Compliance with ethical standards}

Conflict of interest On behalf of all authors, the corresponding author states that there is no conflict of interest.

Open Access This article is distributed under the terms of the Creative Commons Attribution 4.0 International License (http://creative commons.org/licenses/by/4.0/), which permits unrestricted use, distribution, and reproduction in any medium, provided you give appropriate credit to the original author(s) and the source, provide a link to the Creative Commons license, and indicate if changes were made.

\section{References}

Ardhuin F, Stutzmann E, Schimmel M, Mangeney A (2011) Ocean wave sources of seismic noise. J Geophys Res 116:C09004. https://doi.org/10.1029/2011JC006952

Ardhuin F, Balanche A, Stutzmann E, Obrebski M (2012) From seismic noise to ocean wave parameters: general methods and validation. J Geophys Res 117(C5):C05002. https://doi.org/10. 1029/2011JC007449

Ardhuin F, Gualtieri L, Stutzmann E (2015) How ocean waves rock the earth: two mechanisms explain microseisms with periods 3-300 s. Geophys Res Lett 42:765-772. https://doi.org/10.1002/ 2014GL062782

Behr Y, Townend J, Bowen M, Carter L, Gorman R, Brooks L, Bannister S (2013) Source directionality of ambient seismic noise inferred from three-component beamforming. J Geophys Res 118:240-248. https://doi.org/10.1029/2012JB009382

Bensen G, Ritzwoller M, Barmin M, Levshin A, Lin F, Moschetti M, Shapiro NM, Yang Y (2007) Processing seismic ambient noise data to obtain reliable broad-band surface wave dispersion measurements. Geophys J Int 169:1239-1260. https://doi.org/10. 1111/j.1365-246X.2007.03374.x

Bromirski PD, Duennebier FK (2002) The near-coastal microseism spectrum: spatial and temporal wave climate relationships. J Geophys Res 107(B8):2166. https://doi.org/10.1029/ 2001JB000265

Bromirski PD, Duennebier FK, Stephen RA (2005) Mid-ocean microseisms. Geochem Geophys Geosyst 6:Q04009. https:// doi.org/10.1029/2004GC000768

Bromirski PD, Stephen RA, Gerstoft P (2013) Are deep-oceangenerated surface-wave microseisms observed on land? J Geophys Res 118:3610-3629. https://doi.org/10.1002/jgrb.50268

Buffoni C, Schimmel M, Sabbione NC, Rosa ML, Connon G (2018) Rayleigh waves from correlation of seismic noise in Great Island of Tierra del Fuego, Argentina: constraints on upper crustal structure. Geod Geodyn 9:2-12

Campillo M (2006) Phase and correlation in random seismic fields and the reconstruction of the Green function. Pure appl Geophys 163:475-502. https://doi.org/10.1007/s00024-005-0032-8

Cessaro RK (1994) Sources of primary and secondary microseisms. Bull Seism Soc Am 84:142-148

Corela C, Silveira G, Matias L, Schimmel M, Geissler WH (2017) Ambient seismic noise tomography of SW Iberia integrating seafloor- and land-based data. Tectonophysics 700-701:131-149

Derode A, Larose E, Tanter M, De Rosny J, Tourin A, Campillo M, Fink M (2003) Recovering the Green's function from field to field correlations in an open scattering medium. J Acoust Soc Am 113:2973-2976 
Gal M, Reading AM, Ellingsen SP, Gualtieri L, Koper KD, Burlacu R, Tkalĉić H, Hemer MA (2015) The frequency dependence and locations of short-period microseisms generated in the southern ocean and west pacific. J Geophys Res 120:5764-5781. https:// doi.org/10.1002/2015JB012210

Gerstoft P, Tanimoto T (2007) A year of microseisms in southern California. Geophys Res Lett 34:L20304. https://doi.org/10. 1029/2007GL031091

Gimbert F, Tsai VC (2015) Predicting short-period, wind-wavegenerated seismic noise in coastal regions. Earth Planet Sci Lett 426:280-292. https://doi.org/10.1016/j.epsl.2015.06.017

Grad M, Polkowski M, Wilde-Píorko M, Suchcicki J, Arant T (2015) Passive seismic experiment "13 BB star" in the margin of the east European Craton, Northern Poland. Acta Geophys 63:352-373. https://doi.org/10.1515/acgeo-2015-0006

Gualtieri L, Stutzmann E, Capdeville Y, Ardhuin F, Schimmel M, Mangeney A, Morelli A (2013) Modelling secondary microseismic noise by normal mode summation. Geophys $\mathrm{J}$ Int 193:1732-1745. https://doi.org/10.1093/gji/ggt090

Gualtieri L, Stutzmann E, Farra V, Capdeville Y, Schimmel M, Ardhuin F, Morelli A (2014) Modelling the ocean site effect on seismic noise body waves. Geophys J Int 197:1096-1106. https://doi.org/10.1093/gji/ggu042

Gualtieri L, Stutzmann E, Capdeville Y, Farra V, Mangeney A, Morelli A (2015) On the shaping factors of the secondary microseismic wavefield. J Geophys Res Solid Earth. https://doi. org/10.1002/2015JB012157

Halliday D, Curtis A (2008) Seismic interferometry, surface waves, and source distribution. Geophys J Int 175:1067-1087. https:// doi.org/10.1111/j.1365-246X.2008.03918.x

Harmon N, Gerstoft P, Rychert AC, Abers GA, De La Cruz MS, Fischer KM (2008) Phase velocities from seismic noise using beamforming and cross-correlation in Costa Rica and Nicaragua. Geophys Res Lett 35:L19303. https://doi.org/10.1029/ 2008GL035387

Hasselmann K (1963) A statistical analysis of the generation of microseisms. Rev Geophys 1:177-209

Juretzek C, Hadziioannou C (2016) Where do ocean microseisms come from? A study of Love-to-Rayleigh wave ratios. J Geophys Res 121:6741-6756. https://doi.org/10.1002/2016JB013017

Kanamitsu M, Ebisuzaki W, Woollen J, Yang SK, Hnilo JJ, Fiorino M, Potter GL (2002) NCEP-DOE AMIP-II reanalysis. Bull Am Meteor Soc 83:1631-1643

Kedar S, Longuet-Higgins M, Webb F, Graham N, Clayton R, Jones C (2008) The origin of deep ocean microseisms in the North Atlantic Ocean. Proc R Soc A 464:777-793. https://doi.org/10. 1098/rspa.2007.0277

Kimman WP, Campman X, Trampert J (2012) Characteristics of seismic noise: fundamental and highermode energy observed in the northeast of the Netherlands. Bull Seismol Soc Am 102:1388-1399. https://doi.org/10.1785/0120110069

Koper KD, Burlacu R (2015) The fine structure of double-frequency microseisms recorded by seismometers in North America. J Geophys Res Solid Earth 120:1677-1691. https://doi.org/10. 1002/2014JB011820

Koper KD, de Foy B, Benz H (2009) Composition and variation of noise recorded at the Yellowknife Seismic Array, 1991-2007. J Geophys Res 114:B10310. https://doi.org/10.1029/ 2009JB006307

Lacoss RT, Kelly EJ, Toksöz MN (1969) Estimation of seismic noise structure using arrays. Geophysics 34:21-38

Landès M, Hubans F, Shapiro NM, Paul A, Campillo M (2010) Origin of deep ocean microseisms by using teleseismic body waves. J Geophys Res 115:B05302. https://doi.org/10.1029/ 2009JB006918
Lepore S, Markowicz KM, Grad M (2016) Impact of wind on ambient noise recorded by seismic array in northern Poland. Geophys $\mathrm{J}$ Int 205:1406-1413. https://doi.org/10.1093/gji/ggw093

Lepore S, Polkowski M, Grad M (2018) Crustal and uppermost mantle S-wave velocity below the East European Craton in northern Poland from the inversion of ambient-noise records. Int J Earth Sci. https://doi.org/10.1007/s00531-018-1587-9

Li H, Bernardi F, Michelini A (2010) Surface wave dispersion measurements from ambient seismic noise analysis in Italy. Geophys J Int 180:1242-1252. https://doi.org/10.1111/j.1365246X.2009.04476.x

Lin CR, Kuo BY, Liang WT, Chi WC, Huang YC, Collins J, Wang CY (2010) Ambient noise and teleseismic signals recorded by ocean-bottom seismometers offshore Eastern Taiwan. Terr Atmos Ocean Sci 21:743-755. https://doi.org/10.3319/TAO. 2009.09.14.01(T)

Longuet-Higgins MS (1950) A theory on the origin of microseisms. Philos Trans R Soc London 243:1-35

Mcnamara DE, Buland RP (2004) Ambient noise levels in the continental United States. Bull Seismol Soc Am 94:1517-1527

Möllhoff M, Bean CJ (2016) Seismic noise characterization in proximity to strong microseism sources in the northeast Atlantic. Bull Seismol Soc Am 106:14. https://doi.org/10.1785/ 0120150204

Obrebski MJ, Ardhuin F, Stutzmann E, Schimmel M (2012) How moderate sea states can generate loud seismic noise in the deep ocean. Geophys Res Lett 39:L11601. https://doi.org/10.1029/ 2012GL051896

Obrebski M, Ardhuin F, Stutzmann E, Schimmel M (2013) Detection of microseismic compressional (P) body waves aided by numerical modeling of oceanic noise sources. J Geophys Res Solid Earth 118:4312-4324. https://doi.org/10.1002/jgrb.50233

Peterson J (1993) Observations and modeling of seismic background noise. USGS open-file report 93-322, 95p

Retailleau L, Shapiro NM, Guilbert J, Campillo M, Roux P (2014) Antipodal focusing of seismic waves observed with the USArray. Geophys J Int 199:1030-1042. https://doi.org/10.1093/gji/ ggu309

Romanowicz B (2002) Inversion of surface waves: a review. International Handb Earthquake Eng Seismol 81A:149-173

Rost S, Thomas C (2002) Array seismology: methods and applications. Rev Geophys 40:1008. https://doi.org/10.1029/ 2000RG000100

Roux P (2009) Passive seismic imaging with directive ambient noise: application to surface waves and the San Andreas Fault in Parkfield, CA. Geophys J Int 179:367-373. https://doi.org/10. 1111/j.1365-246X.2009.04282.x

Roux P, Sabra KG, Kuperman WA, Roux A (2005) Ambient-noise cross-correlation in free space: theoretical approach. J Acoust Soc Am 117:79-84

Ruigrok E, Campman X, Wapenaar K (2011) Extraction of P-wave reflections from microseisms. C R Geosci 343:512-525. https:// doi.org/10.1016/j.crte.2011.02.006

Sabra KG, Gerstoft P, Roux P, Kuperman WA, Fehler MC (2005a) Extracting time-domain Green's function estimates from ambient seismic noise. Geophys Res Lett 32:L03310. https://doi.org/ 10.1029/2004GL021862

Sabra KG, Roux P, Kuperman WA (2005b) Arrival-time structure of the time-averaged ambient noise cross-correlation function in an oceanic waveguide. J Acoust Soc Am 117:164-174

Schimmel M, Stutzmann E, Ardhuin F, Gallart J (2011a) Polarized Earth's ambient microseismic noise. Geochem Geophys Geosyst 12:Q07014. https://doi.org/10.1029/2011GC003661

Schimmel M, Stutzmann E, Gallart J (2011b) Using instantaneous phase coherence for signal extraction from ambient noise data at a local to a global scale. Geophys J Int 184:494-506 
Schimmel M, Stutzmann E, Ventosa S (2017) Measuring group velocity in seismic noise correlation studies based on phase coherence and resampling strategies. IEEE Trans Geosci Remote Sens. https://doi.org/10.1109/TGRS.2016.2631445

Schulte-Pelkum V, Earle PS, Vernon FL (2004) Strong directivity of ocean-generated seismic noise. Geochem Geophys Geosyst 5:Q03004. https://doi.org/10.1029/2003GC000520

Shapiro NM, Campillo M (2004) Emergence of broadband Rayleigh waves from correlations of the ambient seismic noise. Geophys Res Lett 31:L07614. https://doi.org/10.1029/2004GL019491

Stehly L, Campillo M, Shapiro NM (2006) A study of the seismic noise from its long-range correlation properties. J Geophys Res 111:B10306. https://doi.org/10.1029/2005JB004237

Stutzmann E, Ardhuin F, Schimmel M, Mangeney A, Patau G (2012) Modeling long-term seismic noise in various environments. Geophys J Int 191:707-722. https://doi.org/10.1111/j.1365246X.2012.05638.x

Tanimoto T, Prindle K (2007) Surface wave analysis with beamforming. Earth Planets Space 59:453-458

Van Tiggelen BA (2003) Green function retrieval and time reversal in a disordered world. Phys Rev Lett 91:243904
Ventosa S, Schimmel M, Stutzmann E (2017) Extracting surface waves, hum and normal modes: time-scale phase-weighted stack and beyond. Geophys J Int 211:30-44

Wapenaar K (2006) Green's function retrieval by cross-correlation in case of one-sided illumination. Geophys Res Lett 33:L19304. https://doi.org/10.1029/2006GL027747

Wapenaar K, Fokkema J (2006) Green's function representations for seismic interferometry. Geophysics 71:SI33-SI46. https://doi. org/10.1190/1.2213955

Wessel P, Smith WHF (1998) New, improved version of generic mapping tools released. EOS Trans Am Geophys Union 79:579

Yang Y, Ritzwoller MH (2008) The characteristics of ambient seismic noise as a source for surface wave tomography. Geochem Geophys Geosyst 9:Q02008. https://doi.org/10.1029/2007GC001814

Yao H, van der Hilst RD (2009) Analysis of ambient noise energy distribution and phase velocity bias in ambient noise tomography, with application to SE Tibet. Geophys J Int 179:1113-1132. https://doi.org/10.1111/j.1365-246X.2009.04329.x

Zhan Z, Tsai VC, Clayton RW (2013) Spurious velocity changes caused by temporal variations in ambient noise frequency content. Geophys J Int 194:1574-1581. https://doi.org/10.1093/gji/ggt170 